\title{
PLANEJAMENTO VIRTUAL EM CIRURGIA ORTOGNÁTICA: DIAGNÓSTICO E O PLANEJAMENTO EM 3 DIMENSÕES
}

Samia TASSI, Fernando ANTONINI, Bruno Tochetto PRIMO, Rafaela SCARIOT, Nelson REBELLATO

Os principais objetivos do tratamento ortocirúrgico são 0 estabelecimento de uma oclusão funcional e estável com a concomitante melhora da estética facial. Enquanto os resultados oclusais podem ser objetivamente determinados, estabelecer a estética ideal é muito subjetivo e pode ser visto diferentemente pelo profissional e pelo paciente. A definição dos objetivos comuns e as expectativas com o procedimento proposto são, portanto, parte fundamental do processo de planejamento. Avanços em métodos de diagnóstico e planejamento tem tornado as alterações estéticas mais previsíveis; e programas de planejamento virtual em cirurgia ortognática permitem que o profissional e o paciente visualizem as alterações previstas com antecedência. $O$ presente trabalho não objetiva demonstrar $a$ confiabilidade destes programas através da comparação do planejamento com o resultado obtido, mas sim a apresentação do diagnóstico tridimensional e o planejamento cirúrgico virtual de uma paciente candidata a cirurgia ortognática, em que as limitações da cefalometria tradicional bidimensional foram superadas e os diferentes movimentos cirúrgicos tridimensionais associados ao procedimento proposto foram realizados de forma virtual na etapa de planejamento pré-operatório, tornando o resultado cirúrgico mais previsível e confiável.

Palavras-chave: Odontologia; Cirurgia ortognática; Cefalometria 